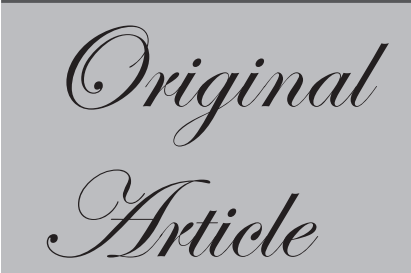

${ }^{1}$ Department of Gastroenterology,

${ }^{2}$ Central Research Laboratory,

Sri Aurobindo Medical College and Post

Graduate Institute, Indore, India.

Correspondence: Dr. Mohd Talha Noor

Email:noorpgi@gmail.com, noorpgi@yahoo.com

\section{Study of role of common NOD2 gene polymorphisms in Indian patients with decompensated liver cirrhosis}

\author{
Manish Tiwari ${ }^{1}$, Mohd Talha Noor ${ }^{1}$, Nivesh Seehra ${ }^{1}$, \\ Sunil Jain ${ }^{1}$, Ravindra Kumar ${ }^{2}$, Bhagwan Singh Thakur ${ }^{1}$
}

\section{ABSTRACT}

Background: Nucleotide-binding oligomerization domain-containing protein 2 (NOD2) gene polymorphisms promote intestinal bacterial translocation (BT). Three common NOD2 gene polymorphisms (R702W, G908R and 1007fs) were recently identified as important genetic risk factors for the occurrence of spontaneous bacterial peritonitis (SBP) and also for poor prognosis in western patients of liver cirrhosis. Our aim was to see the association of these three common NOD2 gene polymorphisms with SBP and other major complications of liver cirrhosis,along with disease prognosis, in Indian population cohort.

Methods: Ninety seven consecutive patients of decompensated liver cirrhosis and 45 healthy controls were recruited. Baseline clinical and laboratory parameters were recorded. Child-Turcotte-Pugh (CTP) and Model for End-Stage Liver Disease (MELD) scores were calculated as disease severity scores. All patients and healthy controls underwent genetic testing for the three common NOD2 gene polymorphisms. Association of these NOD2 gene polymorphisms with major complications of cirrhosis as well as with disease severity, and mortality over 6-months was studied.

Results: Out of the three common NOD2 gene polymorphisms studied, only 1007 fs polymorphism was identified in six (6.18\%) cirrhotic patients. None of the healthy controls showed any of the three polymorphisms. There was no statistically significant association between the presence of 1007 fs polymorphism and major complications of cirrhosis or with disease severity and mortality over 6-months.

Conclusions: Common NOD2 gene polymorphisms are not significantly associated with SBP and other major complications of liver cirrhosis or with poor prognosis.

KEYWORDS: Liver cirrhosis, NOD2 polymorphism, spontaneous bacterial peritonitis. 


\section{Introduction}

Complications related to liver cirrhosis still remain an important cause of mortality worldwide. Ascites, variceal bleeding, spontaneous bacterial peritonitis (SBP), hepatic encephalopathy (HE), hepatorenal syndrome (HRS) and hepatocellular carcinoma (HCC) constitute major complications of cirrhosis. ${ }^{1}$ Development of these complications is associated with decreased longterm survival for patients with cirrhosis. For example, in-hospital mortality for the first episode of SBP ranges from $10 \%$ to $50 \%{ }^{2-5}$ and 1 -year mortality after the first episode of SBP has been reported to be $31 \%$ to $93 \% .^{6-8}$ Similarly, median survival after development of type1 HRS is less than 2 weeks and after type-2 HRS is approximately 6 months. ${ }^{9}$ Various modifiable and nonmodifiable risk factors are involved in the pathogenesis of these complications.

Pathological bacterial translocation (BT) has been termed the "Achilles heel" in cirrhosis ${ }^{10}$ and is reported to play a crucial role in the pathogenesis of various complications of cirrhosis like SBP, HRS, HE and variceal bleeds. ${ }^{11-14}$ Bacterial translocation is defined as translocation of bacteria and/or bacterial products (lipopolysaccharides, peptidoglycans, muramyldipeptides, bacterial DNA etc.) from the gut to mesenteric lymph nodes (MLNs). ${ }^{15} \mathrm{BT}$, together with porto-systemic shunting and reduced hepatic clearance of bacterial products, leads to endotoxemia, with further worsening of hemodynamic parameters in cirrhosis. ${ }^{16}$ The three main mechanisms involved in BT are small intestinal bacterial overgrowth (SIBO), increased intestinal permeability and impaired host defense. ${ }^{17}$ Alterations in both local (intestinal) and systemic immunity promote BT in cirrhosis. Some of these alterations are genetically driven. NOD2 protein which plays an important role in the intestinal innate immunity, recognizes bacterial molecules (peptidoglycans) and stimulates an immune reaction to limit the entry of bacteria across gut by activation of NFkB (nuclear factor-kappa beta) signaling. ${ }^{18}$ Hence, polymorphisms of NOD2 gene may serve as a genetic risk factor for development of complications related to BT in patients with liver cirrhosis.
Three common NOD2 gene polymorphisms (R702W, G908R and 1007fs) have been recently identified as important genetic risk factors for the development of SBP and reduced survival in studies conducted in western populations. ${ }^{19,20}$ These studies have also reported an increased risk of $\mathrm{HCC}$ and recent variceal bleed among patients with NOD2 variants. Similar studies have not been done in the Indian population till date to see the association of common NOD2 gene polymorphisms with SBP or any other major complications of liver cirrhosis, that involve BT in their pathogenesis. Therefore, we conducted this study to find out association of the three common NOD2 gene polymorphisms with major complications of cirrhosis including SBP, HE, HRS, variceal bleeding and HCC as well as with disease severity and prognosis in a cohort of Indian patients with liver cirrhosis.

\section{Methods}

This was a hospital-based prospective study conducted between September 2014 and December 2015 in a tertiarycare hospital in central India. Ninety seven consecutive patients with decompensated liver cirrhosis of age $\geq 18$ years, admitted with various complications were recruited for the study, along with 45 age and gender matched healthy controls. Patients younger than 18 years, pregnant women, those with secondary bacterial peritonitis, ascites of mixed etiology, or extra-hepatic malignancy, patients on long-term antibiotic therapy and those who did not give consent to participate in the study were excluded. The institutional ethical committee approved our study protocol. The study followed the Helsinki Declaration of 1975, as revised in 2000 and 2008, concerning human and animal rights.

Detailed clinical interview and physical examination were performed at the time of admission. Biochemical and serological testing in form of complete hemogram, liver function tests, renal function tests, serum electrolytes and viral markers (HBsAg \& Anti $\mathrm{HCV}$ ) were performed. Diagnosis of cirrhosis was based on clinical, laboratory, ultrasonography \& endoscopic criteria. ${ }^{21}$ The development of complications such as variceal hemorrhage, ascites, hepatic encephalopathy (HE), jaundice, or hepatocellular carcinoma (HCC) 
characterizes decompensated cirrhosis. ${ }^{22}$ Relevant tests were performed to establish the etiology of cirrhosis according to standard criteria. For ascitic fluid cell count, $2.5 \mathrm{ml}$ ascitic fluid was collected in an EDTA vial prior to antibiotic administration, and counts were manually determined microscopically. The concentration of protein and albumin was determined by routine laboratory analysis. For ascitic fluid culture, $10 \mathrm{ml}$ of ascitic fluid was collected in a blood culture bottle at the patients' bedside. Diagnosis of SBP was made when ascitic fluid polymorphonuclear $(\mathrm{PMN})$ count was $\geq 250 / \mu 1$ in the absence of a surgically treatable intra-abdominal source of infection [according to European association for the study of liver (EASL) guideline]. ${ }^{23} \mathrm{HRS}$ and HE were diagnosed using the previously validated standard criteria. ${ }^{24,25}$ Diagnosis of acute on chronic liver failure (ACLF) was made according to criteria established by Asian Pacific Association for the study of liver (APASL) ${ }^{26}$ and diagnosis of $\mathrm{HCC}$ was made according to American association for the study of liver disease (AASLD) criteria. ${ }^{27}$ The severity of the underlying liver disease was assessed according to the Child-Turcotte-Pugh (CTP) score $^{28,29}$ and model for end-stage liver disease (MELD) score. ${ }^{30}$ All patients and healthy controls underwent genetic testing for the three common NOD2 gene polymorphisms (R702W, G908R and 1007fs). Genomic DNA was extracted from EDTAanticoagulated blood using a membrane based extraction kit. $1007 \mathrm{fs}$ and R702W polymorphisms were detected by amplified-refractory mutation system (ARMS) polymerase chain reaction (PCR) using primers shown in Table 1. G908R polymorphism was detected by polymerase chain reaction - restriction fragment length polymorphism (PCR-RFLP) method using primer and restriction enzyme as shown in Table $\mathbf{1 .}$

Difference in frequency of common NOD2 gene variants in patients with cirrhosis and healthy controls was noted, and association of these polymorphisms with major complications of cirrhosis including SBP, HRS, $\mathrm{HE}$, variceal bleed and HCC was assessed. All cirrhotic patients were subdivided into two clinically relevant severity groups according to their CTP $(<10$ or $\geq 10)$ and MELD $(\leq 21$ or $>21)$ score in order to see the association of NOD2 gene polymorphisms with disease severity. All cases were followed up for at least 6-months from admission, and mortality over this period was noted.

Table 1: Primers, PCR product sizes, restriction enzymes and digestionproduct sizes for the three common NOD2 polymorphisms studied.

\begin{tabular}{l|l|l|l|l}
\hline$R 702 W$ & $\begin{array}{l}\text { Forward and reverse primer sequences } \\
\text { Forward Wild: } \\
\text { 5'ATCTGAGAAGGCCCTGCTCC 3' } \\
\text { Forward Mutant: } \\
\text { 5'ATCTGAGAAGGCCCTGCTCT 3' } \\
\text { Common Reverse: } \\
\text { 5'CCCACACTTAGCCTTGATG 3 }\end{array}$ & $439 \mathrm{bp}$ & Restriction enzyme & $\begin{array}{l}\text { Digestion product } \\
\text { size }\end{array}$ \\
\hline G908R & $\begin{array}{l}\text { Forward: } \\
\text { 5'CCCAGCTCCTCCCTCTTC 3' } \\
\text { Reverse: } \\
\text { 5'AAGTCTGTAATGTAAAGCAC 3' }\end{array}$ & $380 \mathrm{bp}$ & - & \\
\hline $1007 f s$ & $\begin{array}{l}\text { Forward Wild: } \\
\text { 5'CAGAAGCCCTCCTGCA GGCCCT 3' } \\
\text { Forward Mutant: } \\
\text { 5'CAGAAGCCCCCTGCAGGCCCCT3' } \\
\text { Common Reverse: } \\
\text { 5'TCTTCAACCACATCCCCATT 3, }\end{array}$ & $333 \mathrm{bp}$ & HhaI & $\begin{array}{l}\text { GG=380bp } \\
\text { GR=380bp+138bp+ } \\
242 \mathrm{bp} \\
\text { RR=130bp+242bp }\end{array}$ \\
\hline
\end{tabular}

PCR - Polymerase chain reaction, NOD2 - Nucleotide binding oligomerization domain containing protein 2. 
Baseline patient characteristics were reported either as median and range for continuous variables or as frequency for discrete variables. All data was organized in Microsoft excel and analyzed using MedCalc software trial version (version 15.6, MedCalc software bvba, Ostend, Belgium). Chi-square test was done to identify association of complications encountered in cirrhosis with the frequency of common NOD2 gene polymorphisms. Statistical tests were based on two-tailed probability. $\mathrm{P}$-value $<0.05$ was taken as significant.

\section{Results}

We studied 97 consecutive adult patients,admitted with various complications related to decompensated liver cirrhosis in the gastroenterology department of our hospital. Baseline clinical and laboratory parameters are shown in Table 2. Majority of patients were male (84.53\%) and had alcohol-related cirrhosis (57.73\%) followed by hepatitis B-related cirrhosis (20.62\%). Ascites (70.10\%) and variceal bleed $(45.36 \%)$ were the most common presentations followed by SBP (23.71\%), HE (19.58\%) and HRS (12.37\%). Ascitic fluid culture was positive in 11 patients. Microbiological profile of ascitic fluid was as follows: Klebsiella Pneumoniae (4 patients), Escherichia Coli (1 patient), Coagulase-negative Staphylococcus Aureus (3 patients), Enterococci (2 patients) and Candida Albicans (1 patient). Out of the three common NOD2 gene polymorphisms studied, only $1007 \mathrm{fs}$ polymorphism was identified in six $(6.18 \%)$ patients of cirrhosis but none of our healthy controls showed any NOD2 gene polymorphism. On subgroup analysis of our data we did not find statistically significant difference in the frequency of the $1007 \mathrm{fs}$ polymorphism in patients with or without complications like SBP, HE, variceal bleed, HRS, ACLF or HCC as shown in Table 3. Furthermore, we did not find any significant association of $1007 \mathrm{fs}$ polymorphism with either severity of liver cirrhosis as assessed by CTP and MELD scores or mortality over 6-months as shown in Table 4.

COX regression analysis was done for identifying the risk factors associated with mortality over 6 months and we found that only MELD and SBP have high hazard ratio, 1.137 (95\%CI 1.054-1.227) and 5.178 (95\%CI 2.212-12.120) respectively as shown in Table 5.

\section{Discussion:}

The present study showed that common NOD2 gene polymorphisms (R702W, G908R and 1007fs) are infrequent in Indian patients of decompensated liver cirrhosis as well as in healthy population. This finding is in concordance with results of earlier studies from India conducted in patients with inflammatory bowel disease. Substantial work has been done in India in the past to see the role of NOD2 gene polymorphisms in patients of inflammatory bowel disease. In a large study conducted in northern India by Juyal et al in 2007, over 298 patients with ulcerative colitis, 25 patients with Crohn's disease and 262 healthy controls reported that the above three common NOD2 gene polymorphisms were infrequent. Only G908R polymorphism was found in 2 patients with ulcerative colitis. ${ }^{31}$ Similarly, a study from southern India by Pugazhendhi et al. among 82 patients of Crohn's disease and 149 controls did not show any of the three common NOD2 gene polymorphisms in patients as well as in healthy controls. ${ }^{32}$

In the present study we did not find statistically significant association of the three common NOD2 gene polymorphisms with any major complication of decompensated liver cirrhosis including SBP, variceal bleeding, HE, HRS, ACLF or HCC. The severity of cirrhosis, assessed by CTP and MELD scores, as well as mortality over 6 months were also independent of the presence of NOD2 gene polymorphism. This is in contrast to earlier reports from western populations. Appenrodt et al had reported that NOD2 variants are genetic risk factors for death and SBP in patients of liver cirrhosis. The occurrence of SBP was increased significantly (P-value $=0.008)$ in carriers of NOD2 variants $(\mathrm{OR}=3.06) .{ }^{19}$ Bruns et al further validated these findings and showed that NOD2 variants increase the risk of culture-positive SBP and bacterial ascites in western populations. They had also reported that carriers of common NOD2 variants have reduced survival as compared to normal wild type genotype. In their study, occurrence of HCC and recent variceal bleed were more common in patients with NOD2 gene variant. ${ }^{20}$ 
Table 2: Baseline characteristics of patients with cirrhosis.

\begin{tabular}{|c|c|}
\hline Total number of study patients (n) & 97 \\
\hline Median age (years), (Range) & $47.5(26-80)$ \\
\hline Gender (Male/Female) & $82 / 15$ \\
\hline \multicolumn{2}{|l|}{ Etiology of cirrhosis, $\mathbf{n}(\%)$} \\
\hline Alcohol & $56(57.73)$ \\
\hline Hepatitis B & $20(20.62)$ \\
\hline Autoimmune & $2(2.06)$ \\
\hline NASH & $6(6.18)$ \\
\hline Cryptogenic & $13(13.40)$ \\
\hline \multicolumn{2}{|l|}{ Presentation, n/total (\%) } \\
\hline Ascites & 68/97 (70.10) \\
\hline Variceal bleed & 44/97 (45.36) \\
\hline $\mathrm{HE}$ & 19/97 (19.58) \\
\hline SBP & 23/97 (23.71) \\
\hline HRS & $12 / 97(12.37)$ \\
\hline ACLF & $14 / 97(14.43)$ \\
\hline $\mathrm{HCC}$ & 7/97 (7.22) \\
\hline \multicolumn{2}{|l|}{ Laboratory parameters } \\
\hline Median Hemoglobin (g/dl), (range) & $8.4(4.9-14.8)$ \\
\hline Median TLC $(\times 1000 / \mu \mathrm{l}),($ range $)$ & $5.7(1-29.8)$ \\
\hline Median Platelets $(\times 1000 / \mu \mathrm{l}),($ range $)$ & $237(21-382)$ \\
\hline Median Creatinine (mg/dl), (range) & $0.75(0.52-4.58)$ \\
\hline Median Sodium (mEq/L), (range) & $135(119-146)$ \\
\hline Median AST (IU/L), (range) & $42.5(20-879)$ \\
\hline Median ALT (IU/L), (range) & $35(14-279)$ \\
\hline Median Bilirubin (mg/dl), (range) & $0.85(0.34-27.74)$ \\
\hline Median Albumin (g/dl), (range) & $2.49(1.38-3.63)$ \\
\hline Median PT (seconds), (range) & $21(14-48)$ \\
\hline Median CTP score (range) & $9.5(6-14)$ \\
\hline Median MELD score (range) & $12.5(6-39)$ \\
\hline \multicolumn{2}{|l|}{$\begin{array}{l}\text { Minor allele frequency of threeNOD2 } \\
\text { gene polymorphisms in total study } \\
\text { patients }(\%)\end{array}$} \\
\hline $\mathrm{R} 702 \mathrm{~W}$ & 0.00 \\
\hline G908R & 0.00 \\
\hline $1007 \mathrm{fs}$ & 6.18 \\
\hline Patients died over 6-months, n/total (\%) & $26 / 97(26.80)$ \\
\hline
\end{tabular}

SBP-Spontaneous bacterial peritonitis, HE-Hepatic encephalopathy, HRS-Hepatorenal syndrome, ACLF-Acute on chronic liver failure, HCC-Hepatocellular carcinoma, TLC-Total leucocyte count, AST-Aspartate aminotransferase, ALT-Alanine aminotransferase, PT-Prothombin time, CTP-Child Turcotte Pugh, MELD-Model for End Stage Liver Disease. 
Table 3: Minor allele frequencyof $1007 \mathrm{fs}$ polymorphism associated with presence or absence of different complications of cirrhosis.

\begin{tabular}{l|l|l|l} 
& $\begin{array}{l}\text { Frequency of } \mathbf{1 0 0 7 f s} \\
\text { polymorphism }(\%)\end{array}$ & OR, $(\mathbf{9 5} \% \mathbf{C I})$ & P-value \\
\cline { 1 - 2 } SBP & 8.7 & $\begin{array}{l}1.667 \\
(0.285-9.746\end{array}$ & 0.567 \\
\hline No SBP & 5.4 & $\begin{array}{l}2.176 \\
(0.368-12.872)\end{array}$ & 0.381 \\
\hline HE & 10.5 & $\begin{array}{l}0.223 \\
(0.025-1.987)\end{array}$ & 0.145 \\
\hline No HE & 5.1 & $\begin{array}{l}1.455 \\
(0.155-13.631)\end{array}$ & 0.741 \\
\hline Variceal bleed & 2.3 & $\begin{array}{l}1.200 \\
(0.130-11.114)\end{array}$ & 0.872 \\
\hline HRS variceal bleed & 9.4 & $\begin{array}{l}2.833 \\
(0.284-28.292)\end{array}$ & 0.356
\end{tabular}

SBP-Spontaneous bacterial peritonitis, HE-Hepatic encephalopathy, HRS-Hepatorenal syndrome, ACLF-Acute on chronic liver failure, HCC-Hepatocellular carcinoma, OR-Odds ratio, CI-Confidence interval.

Table 4: Minor allele frequency of $1007 \mathrm{fs}$ polymorphism associated with severity of cirrhosis (as assessed by CTP and MELD score) and outcome over 6-months.

\begin{tabular}{|c|c|c|c|}
\hline & $\begin{array}{l}\text { Frequency of } 1007 \text { fs } \\
\text { polymorphism }(\%)\end{array}$ & OR, $(95 \%$ CI $)$ & P-value \\
\hline CTP score $<10$ & $2.5 \%$ & \multirow{2}{*}{$\begin{array}{l}3.750 \\
(0.421-33.400)\end{array}$} & \multirow{2}{*}{0.207} \\
\hline CTP score $\geq 10$ & $8.8 \%$ & & \\
\hline MELD score $\leq 21$ & $46.3 \%$ & \multirow{2}{*}{$\begin{array}{l}0.922 \\
(0.160-5.311)\end{array}$} & \multirow{2}{*}{0.927} \\
\hline MELD score $>21$ & $5.9 \%$ & & \\
\hline $\begin{array}{l}\text { Patients survived over } \\
\text { 6- months }\end{array}$ & $34.2 \%$ & \multirow{2}{*}{$\begin{array}{l}2.957 \\
(0.557-15.685)\end{array}$} & \multirow{2}{*}{0.185} \\
\hline $\begin{array}{l}\text { Patients died over } \\
\text { 6-months }\end{array}$ & $11.5 \%$ & & \\
\hline
\end{tabular}

CTP-Child Turcotte Pugh, MELD-Model for End Stage Liver Disease, OR-Odds ratio, CI-Confidence interval.

The failure to find an association between common NOD2 polymorphisms and complications of liver cirrhosis in Indian patients can be explained by the following reasons. First, the pathogenesis of complications in liver cirrhosis is multifactorial and hence inability to find a particular genetic change in a small group of patients is acceptable. The second important fact is the difference in the prevalence of NOD2 gene polymorphisms among different races and in different parts of the world. The three common NOD2 gene polymorphisms are found in up to $30 \%$ patients with Crohn's disease in western populations ${ }^{33}$ but are rare in Asian countries..$^{34,35}$
Table 5: Cox Regression 6-month survival analysis.

\begin{tabular}{l|l|l|l} 
Variables & Hazards Ratio & P-Value & 95\% CI \\
\hline Age & 0.996 & 0.873 & $0.952-1.043$ \\
\hline Gender & 0.479 & 0.313 & $0.115-1.998$ \\
\hline MELD Score & 1.137 & 0.001 & $1.054-1.227$ \\
\hline CTP Score & 0.992 & 0.963 & $0.714-1.380$ \\
\hline SBP & 5.178 & $<0.0001$ & $2.212-12.120$ \\
\hline ACLF & 0.742 & 09.603 & $0.241-2.284$ \\
\hline $\begin{array}{l}\text { NOD2 } \\
(1007 f \text { fs }) \text { gene } \\
\text { polymorphism }\end{array}$ & 1.133 & 0.861 & $0.282-4.542$
\end{tabular}

MELD-Model for End Stage Liver Disease, CTP-Child Turcotte Pugh, SBP-Spontaneous bacterial peritonitis, ACLF-Acute on chronic liver failure, CI-Confidence interval. 
These observations suggest that although the clinical profile of our patients is similar to patients in western studies, the three common NOD2 gene polymorphisms are infrequent and are not associated with major complications in our patients with liver cirrhosis. It is possible that other NOD2 gene polymorphisms or different genetic factors are involved in the development of complications in Indian patients with liver cirrhosis. This warrants further research in larger populations. Our study is limited by its relatively small sample size, a single study center and examination of only 3 NOD2 gene polymorphisms.

In conclusion, the three common NOD2 gene polymorphisms are infrequent and are not associated with SBP and other major complications of decompensated liver cirrhosis or with poor prognosis in our Indian population cohort.

\section{References}

1. Heidelbaugh JJ, Sherbondy M.Cirrhosis and chronic liver failure: part II. Complications and treatment.Am Fam Physician 2006; 74(5): 767-76.

2. Nobre SR, Cabral JE, Gomes JJ, Leitao MC. In-hospital mortality in spontaneous bacterial peritonitis: a new predictive model. Eur J Gastroenterol Hepatol 2008; 20:1176-81.

3. Thuluvath PJ, Morss S, Thompson R. Spontaneous bacterial peritonitis-in-hospital mortality, predictors of survival, and health care costs from 1988 to 1998. Am J Gastroenterol 2001; 96: 1232-6.

4. Tito L, Rimola A, Gines P, Llach J, Arroyo V, Rodes J. Recurrence of spontaneous bacterial peritonitis in cirrhosis: frequency and predictive factors. Hepatology1988; 8:2731.

5. Toledo C, Salmeron JM, Rimola A, Navasa M, Arroyo V, Llach J et al. Spontaneous bacterial peritonitis in cirrhosis: predictive factors of infection resolution and survival in patients treated with cefotaxime. Hepatology 1993; 17: 251-7.

6. Andreu M, Sola R, Sitges-Serra A, Alia C, Gallen M, Vila $\mathrm{MC}$ et al. Risk factors for spontaneous bacterial peritonitis in cirrhotic patients with ascites. Gastroenterol 1993; 104: 1133-8.

7. Silvain $\mathrm{C}$, Besson I, Ingrand $\mathrm{P}$, Mannant $\mathrm{PR}$, Fort $\mathrm{E}$, Beauchant M. Prognosis and long-term recurrence of spontaneous bacterial peritonitis in cirrhosis. J Hepatol 1993; 19: 188-9.

8. Terg R, Levi D, Lopez P, Rafaelli C, Rojter S, Abecasis R et al. Analysis of clinical course and prognosis of culturepositive spontaneous bacterial peritonitis and neutrocytic ascites. Evidence of the same disease. Dig Dis Sci 1992; 37: 1499-504.

9. Charles KF Ng, Michael HM Chan, Morris HL Tie, Christopher WK Lam.Hepatorenal Syndrome. ClinBiochem Rev. 2007; 28(1): 11-17.

10. Benten D, Wiest R. Gut microbiome and intestinal barrier failure-the "Achilles heel" in hepatology? J Hepatol 2012; 56: 1221-1223.

11. Guarner C, Soriano G. Spontaneous bacterial peritonitis. Semin Liver Dis 1997; 17: 203-217.

12. Angeli P, Brun P, Cesari M, Fasolato S, Cavallin M, Castagliuolo L et al. Prevalence of bacterial DNA in patients with cirrhosis and refractory Ascites and its role in the development of cardiac and renal dysfunctions. Hepatology 2010; 52: 342A.

13. Jun DW, Kim KT, Lee OY, Chae JD, Son BK, Kim SH et al. Association between small intestinal bacterial overgrowth and peripheral bacterial DNA in cirrhotic patients. Dig Dis Sci 2010; 55: 1465-71.

14. Thalheimer U, Triantos CK, Samonakis DN, Patch D, Burroughs AK. Infection, coagulation, and variceal bleeding in cirrhosis. Gut 2005; 54: 556-63.

15. Berg RD, Garlington AW. Translocation of certain indigenous bacteria from the gastrointestinal tract to the mesenteric lymph nodes and other organs in a gnotobiotic mouse model. Infect Immun 1979; 23: 403-411.

16. Wiest R, Rath HC. Gastrointestinal disorders of the critically ill. Bacterial translocation in the gut. Best Pract Res Clin Gastroenterol 2003; 17: 397-425

17. Koutsounas I, Kaltsa G, Siakavellas SI, Bamias G. Markers of bacterial translocation in end-stage liver disease. World J Hepatol2015; 7(20): 2264-2273.

18. Ogura $\mathrm{Y}$, Inohara N, Benito A, Chen FF, Yamaoka S, Nunez G. Nod2, a Nod1/Apaf-1 family member that is restricted to monocytes and activates NF-kappaB. J Bio Chem. 2001;276 (7): 4812-8.

19. Appenrodt B, Grünhage F, Gentemann MG, Thyssen L, Sauerbruch T, Lammert F. Nucleotide-binding oligomerization domain containing 2 (NOD2) variants are genetic risk factors for death and spontaneous bacterial peritonitis in liver cirrhosis. Hepatology 2010; 51: 13271333. 
20. Bruns T, Peter J, Reuken PA, Grabe DH, Schuldes SR, Brenmoehl $\mathrm{J}$ et al. NOD2 gene variants are a risk factor for culture-positive spontaneous bacterial peritonitis and monomicrobial bacterascites in cirrhosis. Liver Int2012; 32: $223-230$

21. Udell JA, Wang CS, Tinmouth J, FitzGerald JM, Ayas NT, Simel DL et al. "Does this patient with liver disease have cirrhosis?"JAMA 2012; 307(8): 832-42.

22. Sleisenger and Fordtran. Gastrointestinal and liver disease. Philadelphia. Elsevier Saunders publication. Tenth edition, vol. 2, 2010; p.1257-58

23. Gines P, Angeli P, Lenz K, Moller S, Moore K, Moreau R et al. EASL clinical practice guidelines on the management of ascites, spontaneous bacterial peritonitis and hepatorenal syndrome in cirrhosis. J Hepatol 2010;53: (3): 397-417

24. Salerno F, Gerbes A, Ginès P, Wong F, Arroyo V. Diagnosis, prevention and treatment of hepatorenal syndrome in cirrhosis. Gut 2007; 56: 1310-1318.

25. Cordoba J. New assessment of hepatic encephalopathy. J Hepatol 2011; 54: 1030-1040.

26. Sarin SK, Kedarisetty CK, Abbas Z, Amrapurkar D, Bihari $\mathrm{C}, \mathrm{Chan} \mathrm{AC}$ et al. Acute-on-chronic liver failure: consensus recommendations of the Asian Pacific Association for the study of the liver (APASL) 2014. Hepatol Int. 2014; 8(4): 453-71.

27. Bruix J, Sherman M. Management of hepatocellular carcinoma - An update.Hepatology 2011; 53(3): 10201022.

28. Child CG, Turcotte JG. Surgery and portal hypertension.
In: The liver and Portal Hypertension. Edited by CG child. Philadelphia; Saunders, 1964:50-64.

29. Pugh RN, Murray-Lyon IM, Dawson JL, Pietroni MC, Williams R. Transection of the oesophagus for bleeding oesophageal varices. Br J Surg. 1973; 60:646-9.

30. Malinchoc M, Kamath PS, Gordon FD, Peine CJ, Rank J, ter Borg PC. A model to predict poor survival in patients undergoing transjugular intrahepatic portosystemic shunts. Hepatology 2000; 31: 864-71.

31. Juyal G, Amre D, Midha V, Sood A, Seidman E, Thelma BK. Evidence of allelic heterogeneity for associations between the NOD2/CARD15 gene and ulcerative colitis among North Indians. Aliment PharmacolTher2007; 26:1325-32.

32. Pugazhendhi S, Amte A, Balamurugan R, Subramanian V, Ramakrishna BS. Common NOD2 mutations are absent in patients with Crohn's disease in India. Indian J Gastroenterol2008; 27: 201-203.

33. Bonen DK, Cho JH. The genetics of inflammatory bowel disease. Gastroenterology 2003; 124: 521-36.

34. Sugimura M, Kinouchi Y, Takahashi S, Aihara H, Takagi $\mathrm{S}$, Negoro K et al. CARD15/ NOD2 mutational analysis in Japanese patients with Crohn's disease. Clin Genet 2003; 63:160-2.

35. Inoue N, Tamura K, Kinouchi Y, Fukuda Y, Takahashi S, Ogura Y et al. Lack of common NOD2 variants in Japanese patients with Crohn's disease. Gastroenterology 2002; 123 : 86-91. 